\title{
Effect of Roasting on Oxidative Stability of Pistachio Nut
}

\author{
Eda Adal (Corresponding author) \\ Food Engineering, Gaziantep University, Gaziantep, Turkey \\ E-mail: adal@gantep.edu.tr \\ Fatma Tugba Oksuzler \\ Food Engineering, Gaziantep University, Gaziantep, Turkey \\ E-mail: tugbaoksuzler@hotmail.com \\ Sami Eren \\ Food Engineering, Gaziantep University, Gaziantep, Turkey \\ E-mail: samieren27@gmail.com
}

\begin{abstract}
Pistachio nut (Pistacia vera L.) is one of the most delicious and nutritious nuts in the world. Roasting process enhances the flavor, color, and texture of pistachio nuts and increases overall palatability of the valued products. Oxidative stability is also an important parameter for the quality assessment of pistachio nuts. The main objective of this study is to determine the effect of roasting on the oxidative stability of pistachio samples. For this purpose, pistachio kernels are roasted with two steps industrial roaster at different temperature; $110-120,130-140,150-160^{\circ} \mathrm{C}$. Rancimat Method, which is one of the Accelerated Shelf - Life Test (ASLT) method, was used to determine the oxidative stability of raw and roasted pistachio nut kernel. The induction time (IT) of raw and roasted pistachio samples were automatically recorded at 100,110 , and $120^{\circ} \mathrm{C}$. As the temperature increased induction time was significantly decreased during ASLT $(\mathrm{p}<0.05)$. The roasted pistachio sample was higher IT than IT of raw pistachio sample. Although increasing the oxidative stability with increasing roasting temperature, very high roasting temperature $\left(150-160^{\circ} \mathrm{C}\right)$ decreased IT. As a result, roasting of pistachio nuts improved the oxidative stability of the nut.
\end{abstract}

Keywords: Pistachio nut, roasting, oxidative stability, Rancimat method

DOI: $10.7176 /$ JSTR/5-5-14

\section{Introduction}

Pistachio nut (Pistacia vera L.) is one of the most delicious and nutritious nuts in the world. Roasted and salted or unsalted pistachio nuts are usually directly consumed as snack foods. The non-split pistachio form is used in the production of pistachio oil, pistachio butter, pistachio chocolate, and pistachio halva. It is also added as an ingredient in the sausage, confectionery and sauces industries. Turkey is one of the leading countries that produce pistachio nuts with annual output of 150,000 tons (FAO, 2014).

Fats, oils, and lipid containing foods are oxidized at different rates which results in their sensory and nutritional deterioration. One of the most important parameters that influence lipid oxidation is the degree of unsaturation of fatty acids involved. Oxidative stability is an important parameter for the quality assessment of fats and oils. Autoxidation is affected by atmospheric oxygen and the oxidation process proceeds via free radical reactions involving unsaturated fatty acids. Generally, tree nut oils are somewhat similar to peanut oil and are rich in monounsaturated fatty acids, predominantly oleic acid, but contain much lower amounts of polyunsaturated fatty acids, such as linoleic acid, and small amounts of saturated lipids. Therefore, the most important problem of pistachio nut is lipid oxidation (List et al., 2005; Shahidi et al., 2010).

For this study, the sample was prepared as that pistachio kernels were roasted $110-120^{\circ} \mathrm{C}, 130-140^{\circ} \mathrm{C}$ and $150-160^{\circ} \mathrm{C}$, which are used as industrial roasting temperature. In addition, Rancimat Method, which is one of the Accelerated Shelf - Life Test (ASLT) method, was used to determine the oxidative stability of raw and roasted pistachio nut kernel. The induction time of raw and roasted pistachio samples were automatically recorded at 100,110 , and $120^{\circ} \mathrm{C}$. As a result, roasting of pistachio nuts improved the oxidative stability of the resultant nut oils. 


\section{Materials\&Methods}

\subsection{Materials}

Main material pistachio kernels were obtained from the Asım Samlı Agricultural Products Export, Import and Trading, SA, (Gaziantep, Turkey). Pistachio kernels, "kırmız”" (Nizip, August 2013 crop) type, 16 $\mathrm{mm}$ length, $9 \mathrm{~mm}$ height and $6 \mathrm{~mm}$ width in size.

All chemicals used in this study were of analytical grade and purchased from Merck Chemical Co. (Darmstadt, Germany).

\subsection{Methods}

\subsubsection{Sample preparation and storage conditions}

Pistachio kernels were roasted in industrial hot-air two-step roaster at $110-120^{\circ} \mathrm{C}$ for 48 minutes, 130 $140^{\circ} \mathrm{C}$ for 35 minutes and $150-160^{\circ} \mathrm{C}$ for 23 minutes. Control sample was also used to raw pistachio kernel. All samples were tightly vacuumed and sealed in the vacuum bags and were placed to the refrigerator at $4^{\circ} \mathrm{C}$ until usage.

\subsubsection{Oil extraction for chemical analysis}

$200 \mathrm{~g}$ of each sample was first ground into a fine powder and $400 \mathrm{~mL}$ hexane was added. The resulting mixtures were waited for 24 hours to extract oil from grounded kernels. After 24 hours, the mixtures were filtered through a Whatman no. 42 filter paper for two times. The residue was re-extracted twice by the same solvent; the filtrates from three extractions were combined. The solvent was removed from the solvent-oil mixture by using a rotary evaporator (Heidolph Laborota 4000 Efficient, Germany) at $40^{\circ} \mathrm{C}$. The resulting oil was stored at $4^{\circ} \mathrm{C}$ until use (Miraliakbari and Shahidi, 2008).

\subsubsection{Chemical Analysis}

\subsubsection{Moisture Content Determination}

The moisture content was determined by the oven method according to Official method of analysis (AOAC, 1995). The measurements were carried out in triplicate.

\subsubsection{Protein Determination}

The protein content was determined by the Kjeldahl method. The nitrogen rate in samples was measured, the obtained number for sample was multiplied in protein factor 6.25 and the amount of protein in sample was obtained according to Official method of analysis (AOAC, 1995). The measurements were carried out in triplicate.

\subsubsection{Oil Content Determination}

The oil content of pistachio kernel was determined according to TS 973 EN ISO 659 using Solvent extractor (Ser 148-6, Velp Scientifica, Italy) (Turkish Standard, 2000). The measurements were carried out in triplicate.

\subsubsection{Total Ash Content Determination}

The total ash content of the pistachio kernel samples was determined using the dry ashing method (AOAC, 1995). About $2 \mathrm{~g}$ (dry weight basis) of the sample was weighed into a porcelain crucible. The crucibles containing the samples were placed in a high temperature muffle furnace heated to $800^{\circ} \mathrm{C}$ for $6 \mathrm{~h}$. The ash content was then determined and expressed as Percentage ash=(Mass of ash/Mass of dry sample) $\mathrm{x} 100$.

\subsubsection{Oxidative Measurement (Rancimat Method)}

A metrohm Rancimat model 743 (Herisau, Switzerland) capable of operating over a temperature range of $50-220^{\circ} \mathrm{C}$ was used in this study. The glassware was rigorously cleaned between each run to avoid any contamination that would catalyze the peroxidation. The tubes were cleaned with acetone after each run and then washed off with washing liquid in hot water. The washed tubes were rinsed with distilled water and dried in the oven. Measuring vessels, electrodes, and connecting tubes were cleaned several times with alcohol and distilled water.

Determination of the oxidative stability of pistachio oil by the Rancimat method was carried according to AOCS Cd 12b-92 method (AOCS, 1995). A stream of air was bubbled into $3 \mathrm{~g}$ of oil samples in a reaction vessel placed in an electric heating block. Effluent air containing volatile organic acids from the oil sample was collected in a measuring vessel containing distilled water $(60 \mathrm{~mL})$. The conductivity of 
water was measured automatically as oxidation proceeded. Filtered, cleaned, dried air was allowed to bubble through the hot oil at rates of $20 \mathrm{~L} / \mathrm{h}$. The induction time of the oil samples haswas automatically recorded at 100,110 , and $120^{\circ} \mathrm{C}$ for each sample that roasted at different temperature. For each time studied, eight samples were accommodated in the equipment and analyzed simultaneously (Farhoosh, 2007).

\subsection{Statistical Analysis}

The results were compared by the multifactor analysis of variance (multifactor ANOVA) to test for significant differences. Means of the groups were compared using Duncan's multiple range test using an SPSS statistical packet (version 22.0) (IBM Software, NY, USA). Differences among sample means were reported to be significant when $\mathrm{p}<0.05$ and Microsoft Office program used for drawing plots.

\section{Results and Discussions}

\subsection{Moisture Content of Pistachio}

The moisture content of pistachio kernel before roasting was $5.48 \%$ on wet basis. Roasting temperature and time were adjusted to obtain the same final moisture content of all pistachio samples. Pistachio sample which roasted at $110-120^{\circ} \mathrm{C}$ for 48 minutes had $2.6 \%$ moisture content in wet basis after the roasting process. The second pistachio sample whose roasting condition was at $130-140^{\circ} \mathrm{C}$ for 35 minutes had $1.8 \%$ moisture content in wet basis. The moisture content of the last sample which was roasted at $150-160^{\circ} \mathrm{C}$ for 23 minutes was $1.7 \%$ in wet basis after the roasting process. The moisture content of pistachio kernel changes between 1.5-3.0\% based on customer demand and usage purpose (Anonyms, 2013).

\subsection{Protein content of Pistachio}

The protein content of pistachio sample was found $23.6 \%$ in dry matter $(\mathrm{dm})$. In the study of Küçüköner and Yurt (2003), the protein content of pistachio nuts was found between $20.18-23.62 \%$. In addition, Maskan and Karataş (1999) obtained 21.7\% protein content of pistachio in their study. Seferoğlu et al. (2006) also determined the protein content of different type pistachio between 23.2-31.7\% on dry basis. The other study whose is Tsantili et al. (2010) showed that the protein content of pistachio was between $18.99-21.87 \%$ in dry matter. The small difference in protein content results arises due to different kind pistachio kernels.

\subsection{Oil Content of Pistachio}

The oil content of pistachio sample which was used in this study was determined as $46 \%$. Tsantili et al. (2010) were reported oil content as ranged from $49.79 \%$ to $57.62 \%$ in $\mathrm{dm}$. In a study carried out by Seferoğlu et al. (2006) was showed oil content between 46.8 and $66.5 \%$ in dry weight. According to Maskan and Karataş (1999), the oil content was found 57.4\%. All these studies have been shown that pistachio kernel has high oil content, ranged between 46 and $66 \%$. The pistachio kernel used in this study has low oil content because of the type of pistachio.

\subsection{Total Ash Content of Pistachio}

The ash content of pistachio was obtained as $2.6 \%$ in $\mathrm{dm}$. Also, Maskan and Karataş (1999) were also determined $2.31 \%$ which was near the result of this study. In the study of Seferoğlu et al. (2006), the ash content is showed as ranged from $3.1-3.9 \%$ in dry matter.

\subsection{Oxidative Stability Measurements}

The oxidation of lipids has several important consequences for food quality and acceptability. The oxidative stability of food is, therefore, an important parameter in determining its shelf life and quality (Verleyen et al., 2005). The oxidative stability index (OSI), which is a result of Rancimat methods is correlated with oxidative stability under various conditions of lipid oxidation and also with data obtained from independent sensory and/or analytical methods (Farhoosh, 2007). The end point of the IT (h) was characterized by the sudden increase of water conductivity $(\mu \mathrm{S} / \mathrm{cm})$, due to the dissociation of volatile carboxylic acids as seen in Figure 1.

The IT of pistachio kernel samples raw and roasted at different temperature are presented in Table 1. 
Table 1. The IT of pistachio samples at different temperature.

\begin{tabular}{llll}
\hline Pistachio type & \multicolumn{2}{l}{ Temperature $\left({ }^{\circ} \mathbf{C}\right)$} & \\
\cline { 2 - 4 } & 100 & 110 & 120 \\
Raw & $43.21^{\mathrm{aA}}$ & $18.88^{\mathrm{aB}}$ & $9.35^{\mathrm{aC}}$ \\
Roasted $\left(\mathbf{1 1 0 - 1 2 0 ^ { \circ }} \mathbf{C}\right)$ & $59.49^{\mathrm{bA}}$ & $28.80^{\mathrm{bB}}$ & $14.76^{\mathrm{bC}}$ \\
Roasted $\left.^{\left(130-140^{\circ}\right.} \mathbf{C}\right)$ & $66.52^{\mathrm{cA}}$ & $33.22^{\mathrm{cB}}$ & $17.98^{\mathrm{cC}}$ \\
Roasted $\left.^{\left(150-160^{\circ}\right.} \mathbf{C}\right)$ & $62.09^{\mathrm{bcA}}$ & $26.03^{\mathrm{dB}}$ & $13.01^{\mathrm{bC}}$ \\
\hline
\end{tabular}

Means followed by the same small letter within same line are not significantly different at 0.05 significance level according to Duncan's multiple range test.

Means followed by the same capital letter within same column are not significantly different at 0.05 significance level according to Duncan's multiple range test.

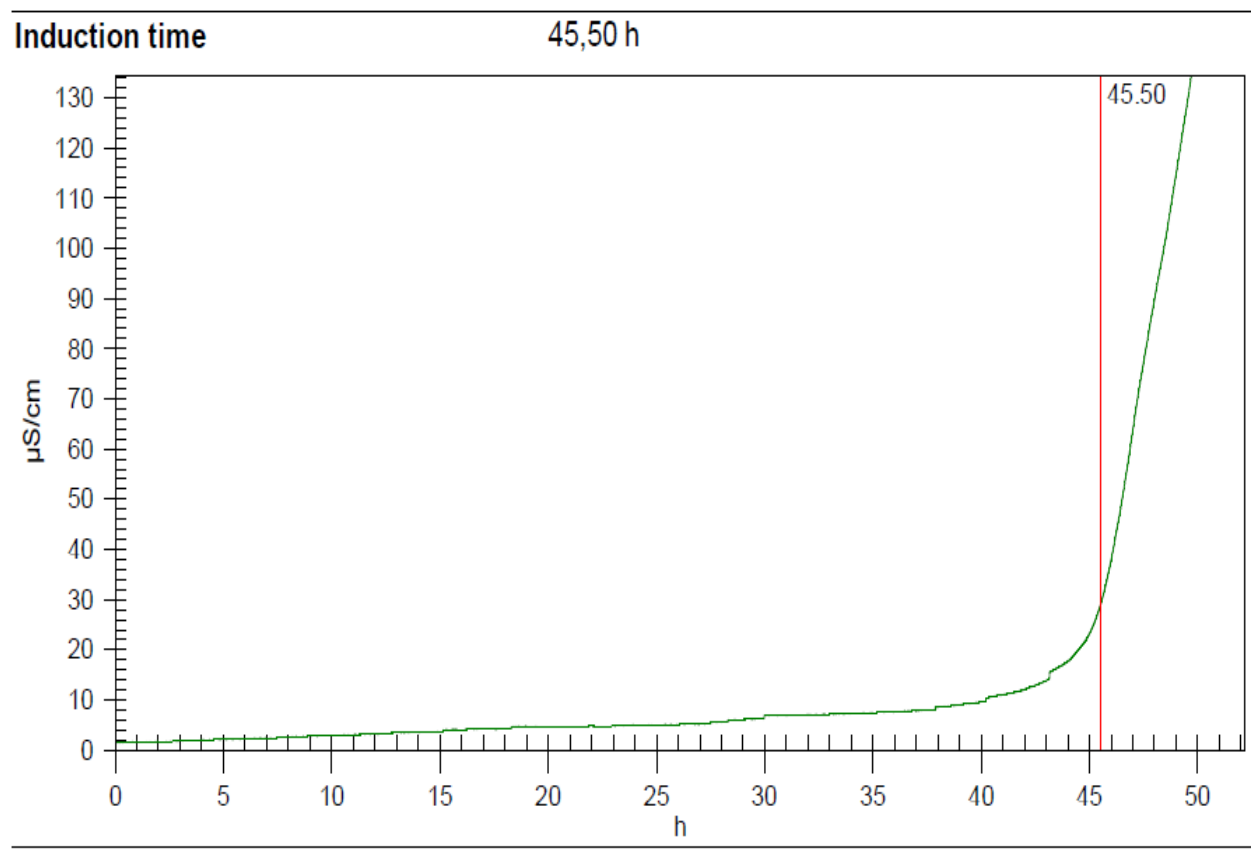

Figure 1. The typical output result of Rancimat.

The induction time of raw pistachio kernel was 43.21 hour (h) at $100^{\circ} \mathrm{C}$ Rancimat temperature. The induction time of roasted kernel at $110-120^{\circ} \mathrm{C}$ and $130-140^{\circ} \mathrm{C}$ significantly increased to 59.49 and 66.52 $\mathrm{h}$, respectively $(\mathrm{p}<0.05)$. In samples with roasted at $150-160^{\circ} \mathrm{C}$, there was a slight decrease in induction time with increasing roasting temperature, it decreased to $62.09 \mathrm{~h}(\mathrm{p}<0.05)$. The highest induction time $(66.52 \mathrm{~h})$ was observed in the sample which was roasted at $130-140^{\circ} \mathrm{C}$ (Figure 2).

The induction time of raw pistachio kernel was $18.88 \mathrm{~h}$ at $110^{\circ} \mathrm{C}$ Rancimat temperature. The induction time of roasted kernel at $110-120^{\circ} \mathrm{C}$ significantly increased to $28.80 \mathrm{~h}(\mathrm{p}<0.05)$. In samples roasted at $130-140^{\circ} \mathrm{C}$, the induction time significantly increased to $33.22 \mathrm{~h}(\mathrm{p}<0.05)$. There was a slight decrease to $26.03 \mathrm{~h}$ in induction time of sample roasted at $150-160^{\circ} \mathrm{C}$ with increasing roasting temperature $(\mathrm{p}<0.05)$. The highest induction time $(33.22 \mathrm{~h})$ was observed in the sample which was roasted at 130 $140^{\circ} \mathrm{C}$ (Figure 3 ). The effect of high roasting temperature reduced oxidative stability whereas it was higher than oxidative stability of raw pistachio kernel as observed as at $100^{\circ} \mathrm{C}$ Rancimat temperature.

The induction time of raw pistachio kernel was $9.35 \mathrm{~h}$ at $120^{\circ} \mathrm{C}$ Rancimat temperature. The induction time of roasted kernel at $110-120^{\circ} \mathrm{C}$ significantly increased to $14.76 \mathrm{~h}(\mathrm{p}<0.05)$. In samples roasted at $130-140^{\circ} \mathrm{C}$, there was a significant increase to $17.98 \mathrm{~h}$ in induction time $(\mathrm{p}<0.05)$. There was a slight decrease to $3.01 \mathrm{~h}$ in induction time of sample roasted at $150-160^{\circ} \mathrm{C}$ with increasing roasting temperature 
$(\mathrm{p}<0.05)$.The highest induction time $(17.8 \mathrm{~h})$ was observed in the sample which roasted kernel at 130 $140^{\circ} \mathrm{C}$ and the lowest one $(9.35 \mathrm{~h})$ in raw pistachio kernel (Figure 4). The effect of high roasting temperature again reduced oxidative stability whereas it was higher than oxidative stability of raw pistachio kernel at $120^{\circ} \mathrm{C}$ Rancimat temperature.

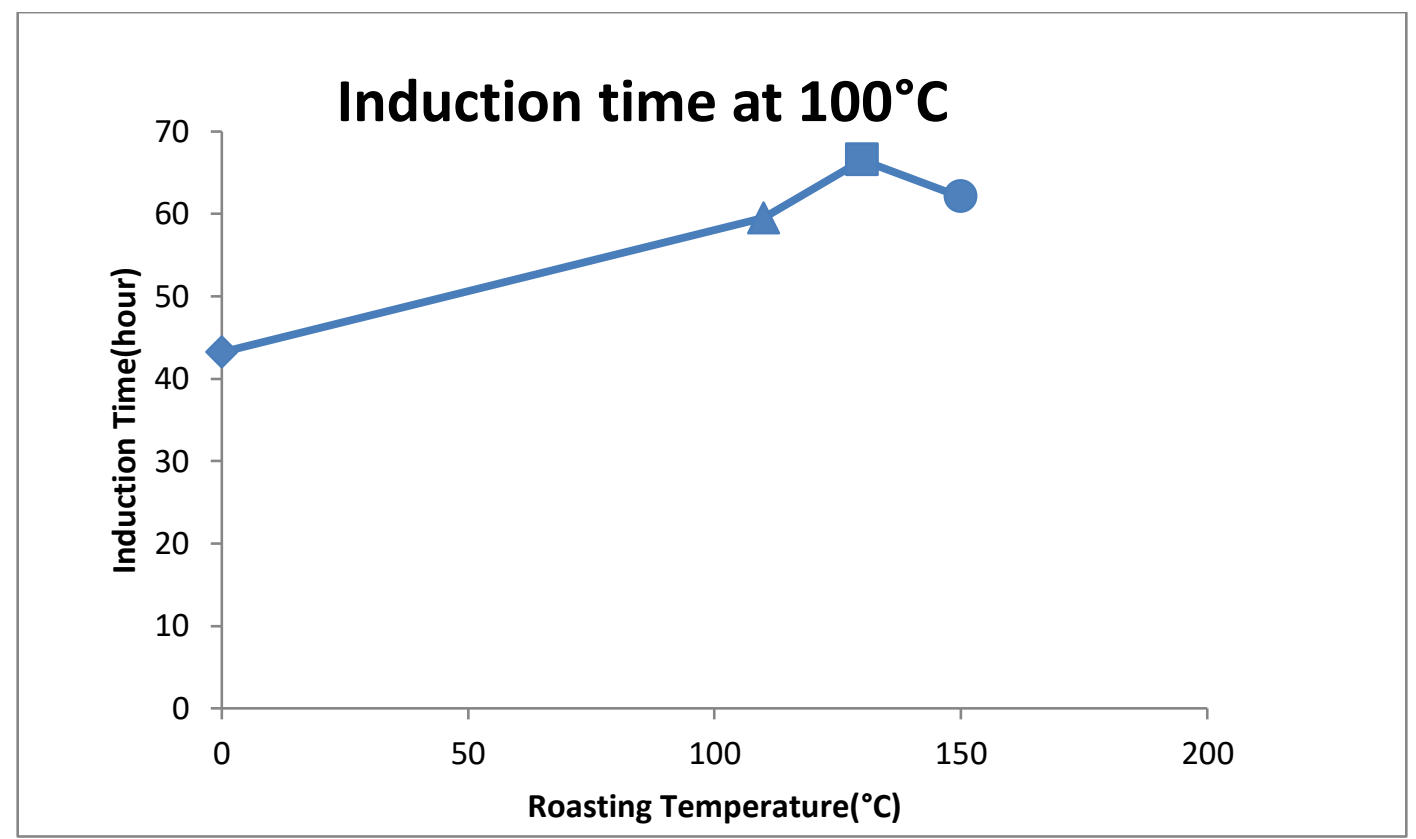

Figure 2. Plot of IT (hour) versus raw and roasting process temperature for $100^{\circ} \mathrm{C}$ Rancimat operating temperature.

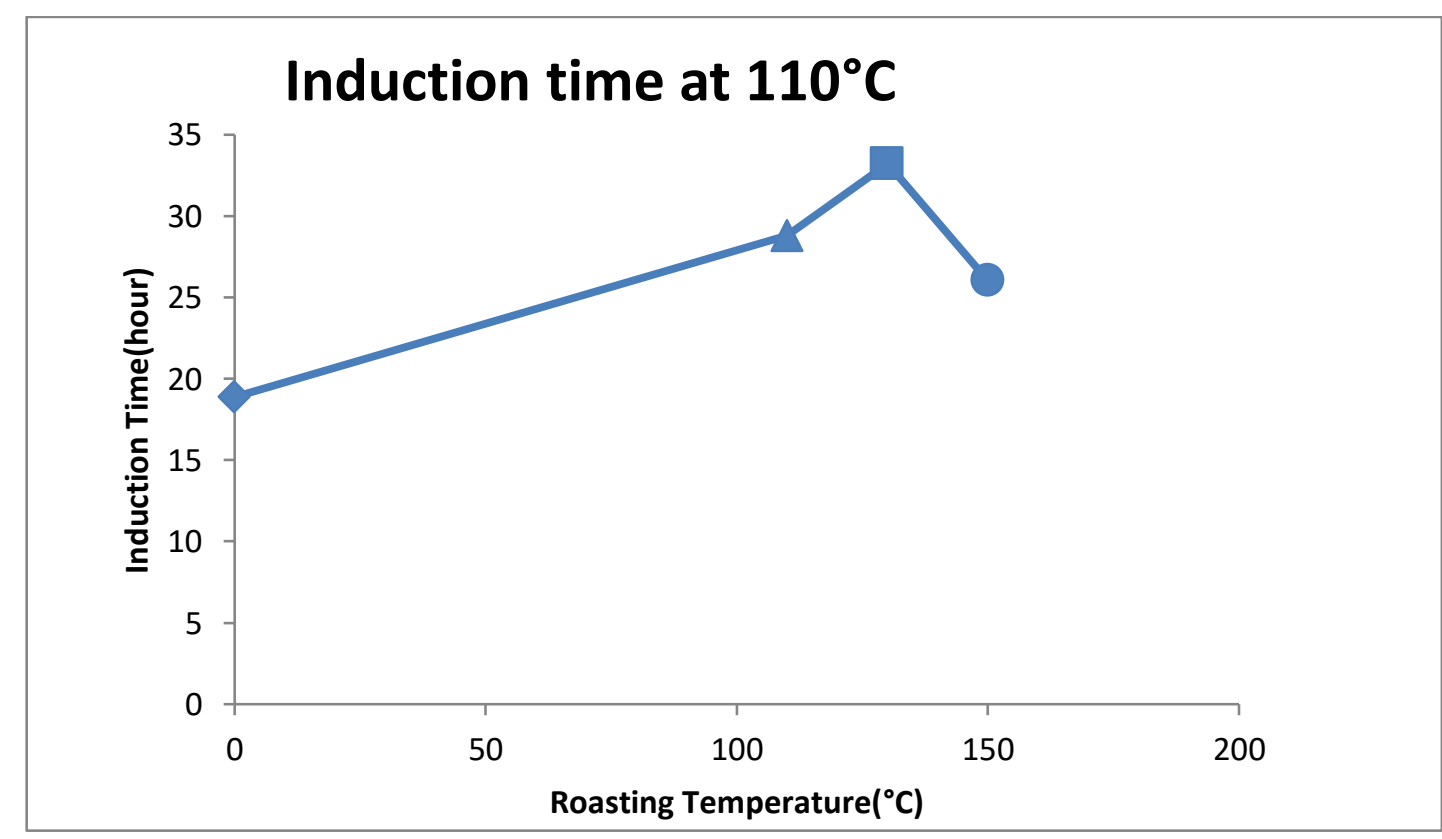

Figure 3. Plot of IT (hour) versus raw and roasting process temperature for $110^{\circ} \mathrm{C}$ Rancimat operating temperature. 


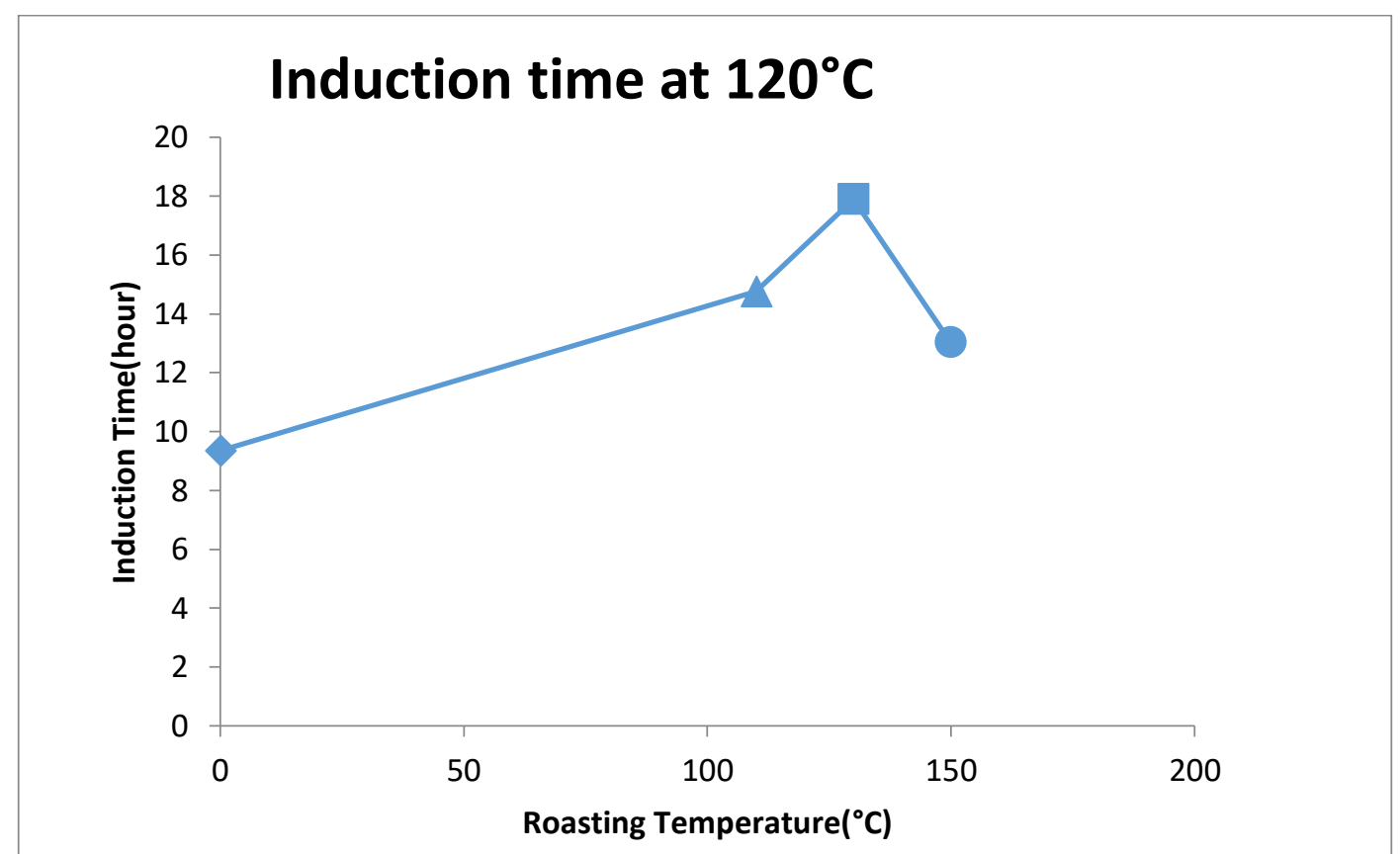

Figure 4. Plot of IT (hour) versus raw and roasting process temperature at $120^{\circ} \mathrm{C}$ Rancimat operating temperature.

The induction time of all raw and roasted pistachio samples was shown at Figure 5. by increasing operating temperature of Rancimat device significantly decreased, as would expect, IT of sample $(p<0.05)$. Similar results were found by Farhoosh (2007), these decreasing indicate that the conditions under which the oil sample oxidizes vary with temperature. In addition, the lowest IT was own to raw pistachio sample as expected. As a result of IT, it was observed that the roasting process enhance the oxidative stability of pistachio kernel.

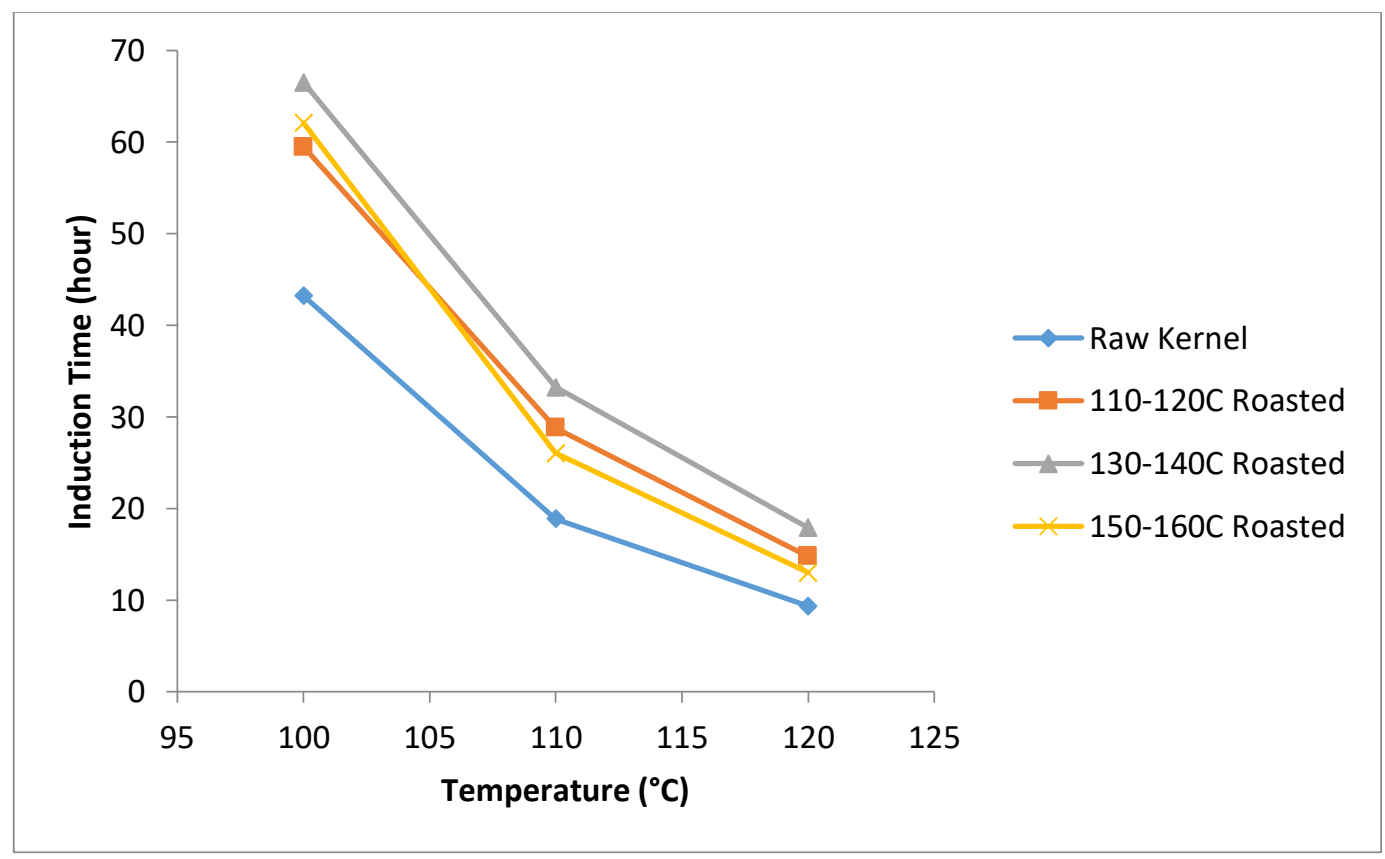

Figure 5. Plot of IT (hour) versus Rancimat operating temperature for raw and roasted pistachio samples. 
The study carried out by Durmaz and Gökmen (2011) was also showed that roasting increases stability due to Maillard reaction products (MRPs). One of the main desired outcomes of the roasting process is the increase in antioxidant activity that occurs mainly due to the formation of MRPs. The Maillard reaction takes place in oily seeds by the interaction of carbonyls with amines during thermal processing. Volatile MRPs are expected to increase the oxidative stability of the oil by terminating lipid oxidation reactions (Durmaz and Gökmen, 2011). Besides the formation of MRPs, roasting may change the total antioxidant capacity of oils by increasing or decreasing the passage of naturally occurring antioxidant phytochemicals to the oil. Meanwhile, heat pretreatment was reported to decrease the lipolytic enzyme activities in extracted oil that also provide better oxidative stability to the oils extracted from roasted seeds and nuts (Veldsink et al., 1999).

The other study of Durmaz et al. (2010) stated that the shelf life of oily nuts and seeds could be improved by an appropriate roasting. The oxidative stability of rapeseed, sunflower, sesame, and safflower oils was enhanced by heat treatment prior to oil extraction. Roasting of the seeds prior to the oil extraction improved the heat stability of the mustard seed oil, along with tocopherols and lutein content.

Both the increase in temperature and roasting time led to an enhanced IT value and had high oxidative stability. It could be explained by the fact that the roasting process of pumpkin seeds leads to the formation of products with antioxidative properties. Maillard reaction products are well known potent natural antioxidants and could possibly contribute to the high oxidative stability of the oil (Vujasinovic et al, 2012).

Therefore, the oils from cashew nut roasted at high temperatures had a significantly higher oxidative stability than oil from raw cashew nuts or those roasted at a low temperature. These results were also shown that oxidative stability increase with increasing roasting temperature (Chandrasekara and Shahidi, 2011).

In the study of Rosales-Martínez et al. (2014), the amount of total phenols increased with the roasting process in both varieties, this may be because the temperature can lead to changes in the structure that result in greater availability of antioxidant compounds, which are phenolic compounds. Many antioxidant compounds in plants are mainly present as covalently bound forms with insoluble polymers. It is possible that heat disrupts the cell wall and releases antioxidant compounds, leading to an increase in antioxidant capacity. Raw peanut antioxidant capacity was minor than the roasted samples.

As seen in Figure 5, the highest oxidative stability was observed in the $130-140^{\circ} \mathrm{C}$ roasting process. IT at $150-160^{\circ} \mathrm{C}$ roasting process is higher than IT of raw pistachio kernels. But nevertheless, IT at $150-$ $160^{\circ} \mathrm{C}$ roasting condition was lower than IT at $110-120^{\circ} \mathrm{C}$ and $130-140^{\circ} \mathrm{C}$ due to high heat treatment. Although the roasting process increases the oxidative stability of pistachio kernel, this study showed that very high-temperature roasting process results in low oxidative stability.

Gentile et al. (2007) also indicated that a comparative study between raw and roasted pistachio, reporting that the heat treatment $\left(160^{\circ} \mathrm{C}, 40 \mathrm{~min}\right)$ decreases the phenolic content and antioxidant capacity, showing a total loss of vitamin $\mathrm{C}$ and proanthocyanidins, which contribute to the total antioxidant activity.

The study of Açar et al. (2009) was represented that net effect of roasting on the total antioxidant capacity of oilseeds depends on the balance between the thermal degradation of naturally occurring antioxidant compounds and the formation of new MRPs having antioxidant capacity. Moreover, the other study said that higher antioxidant concentration in oils extracted from roasted seeds compared to unroasted ones is generally attributed to the cellular deformations which take place during the roasting process which facilitates extractability of those phytochemicals along with the oil (Chiou \& Tsai, 1989).

At the same time, the roasting process produced an increase in the primary and secondary oxidation products (very undesirable in oil), resulting in higher Totox values, nevertheless these values are still low and not of concern for the investigated oils (Vujasinovic et al, 2012).

Park et al. (2011) showed that the roasting conditions of perilla seeds at higher temperatures, up to $210^{\circ} \mathrm{C}$, and have concluded that at higher temperatures, above $170^{\circ} \mathrm{C}$, much darker and more oxidized oils are produced. At the higher roasting temperatures, the longer duration of the process resulted in a higher content of phenolics in the virgin hull-less pumpkin oils, as it was also demonstrated by Vujasinovic et al. (2012).

\section{Conclusion}

In the present study, raw and roasted pistachio nut samples were examined for their oxidative stability. The results showed that the roasting process improved the stability of the pistachio kernel. During roasting process, Maillard reaction is interaction of carbonyls with amines and produce Maillard reaction

141 | P a g e

www.iiste.org 
products enhanced antioxidant capacity. Thus, roasting process prevented lipid oxidation and enhanced oxidative stability of pistachio kernels. This study also indicated that the roasting temperature was also important parameter for improving of oxidative stability. The oxidative stability of roasted pistachio kernel at very high temperature $\left(150-160^{\circ} \mathrm{C}\right)$ was lower than the oxidative stability of roasted pistachio kernel at $130-140{ }^{\circ} \mathrm{C}$ although it was higher than oxidative stability of raw pistachio kernel. Therefore, the medium roasting of pistachio kernels improve the oxidative stability of pistachio kernels.

\section{ACKNOWLEDGMENTS}

Authors declare that there are no present or potential conflicts of interest among them and other people or organizations that could inappropriately bias their work. Authors would also like to thank Asim Samli Agricultural Products Import, Export \& Trading Inc. for their help and support during rancimat experiments.

This research did not receive any specific grant from funding agencies in the public, commercial, or notfor-profit sectors.

\section{References}

Açar, Ö. Ç., Gökmen, V., Pellegrini, N., \& Fogliano, V. (2009). Direct evaluation of the total antioxidant capacity of raw and roasted pulses, nuts and seeds. European Food Research and Technology, 229(6), 961-969.

AOAC (1995). Official methods of analysis (16th. ed.). Arlington, VA: Association of Official Analytical Chemists.

AOCS (1995). Official methods and recommended practices of the American Oil Chemists' Society. Champaign: American Oil Chemists' Society.

Anonyms (2013). Asım Samlı Agricultural Products Export, Import And Trading, Sa roasted pistachio kernel production method.

Chandrasekara, N., \& Shahidi, F. (2011). Antioxidative potential of cashew phenolics in food and biological model systems as affected by roasting. Food Chemistry, 129(4), 1388-1396.

Chiou, R. Y., \& Tsai, T. T. (1989). Characterization of peanut proteins during roasting as affected by initial moisture content. Journal of agricultural and food chemistry, 37(5), 1377-1381.

Durmaz, G., Karabulut, İ., Topçu, A., Asiltürk, M., \& Kutlu, T. (2010). Roasting related changes in oxidative stability and antioxidant capacity of apricot kernel oil. Journal of the American Oil Chemists' Society, 87(4), 401-409.

Durmaz, G., and Gökmen, V. (2011). Changes in oxidative stability, antioxidant capacity and phytochemical composition of $<$ i $>$ Pistacia terebinthus $</ \mathrm{i}>$ oil with roasting. Food chemistry, 128(2), 410-414.

FAO (2014). FAOSTAT online statistical service. Food and Agriculture Organization of the United Nations. Available via URL. http://faostat.fao.org/. Accessed December 2014.

Farhoosh, R. (2007). The effect of operational parameters of the Rancimat method on the determination of the oxidative stability measures and shelf-life prediction of soybean oil. Journal of the American Oil Chemists' Society, 84(3), 205-209.

Gentile, C., Tesoriere, L., Butera, D., Fazzari, M., Monastero, M., Allegra, M., and Livrea, M. A. (2007). Antioxidant activity of Sicilian pistachio (Pistacia vera L. var. Bronte) nut extract and its bioactive components. Journal of agricultural and food chemistry, 55(3), 643-648

Küçüköner, E., and Yurt, B. (2003). Some chemical characteristics of Pistacia vera varieties produced in Turkey. European Food Research and Technology,217(4), 308-310. 
List, G. R., Wang, T., and Shukla, V. K. (2005). Storage, handling, and transport of oils and fats. Bailey's Industrial Oil and Fat Products.

Maskan, M., and Karataş, Ş. (1999). Storage stability of whole-split pistachio nuts $(<\mathrm{i}>$ Pistachia vera $</$ i $>$ L.) at various conditions. Food chemistry, 66(2), 227-233.

Park, M. H., Seol, N. G., Chang, P. S., Yoon, S. H., \& Lee, J. H. (2011). Effects of roasting conditions on the physicochemical properties and volatile distribution in perilla oils (Perilla frutescens var. japonica). Journal of food science, 76(6), C808-C816.

Rosales-Martínez, P., Arellano-Cárdenas, S., Dorantes-Álvarez, L., García-Ochoa, F., \& LópezCortez, M. D. S. (2014). Comparison between antioxidant activities of phenolic extracts from Mexican peanuts, peanuts skins, nuts and pistachios. Journal of the Mexican Chemical Society, 58(2), 185-193.

Shahidi, F., John, J. A., Decker, E. A., Elias, R. J., and McClements, D. J. (2010). Oxidation and protection of nuts and nut oils. Oxidation in foods and beverages and antioxidant applications. Volume 2: Management in different industry sectors, 274-305.

Miraliakbari, H., and Shahidi, F. (2008). Oxidative stability of tree nut oils. Journal of Agricultural and Food Chemistry. 56, pp.4751-4759.

Seferoglu, S., Seferoglu, H. G., Tekintas, F. E., and Balta, F. (2006). Biochemical composition influenced by different locations in Uzun pistachio cv.(Pistacia vera L.) grown in Turkey. Journal of Food Composition and Analysis, 19(5), 461-465.

Tsantili, E., Takidelli, C., Christopoulos, M. V., Lambrinea, E., Rouskas, D., and Roussos, P. A. (2010). Physical, compositional and sensory differences in nuts among pistachio (Pistachia vera L.) varieties. Scientia horticulturae, 125(4), 562-568.

Turkish Standard (2000). Oilseeds- Determination of oil content (reference methods), Türk Standartları Enstitüsü, Bakanlıklar, Ankara.

Veldsink, J. W., Muuse, B. G., Meijer, M. M. T., Cuperus, F. P. et al., Heat pretreatment of oilseeds: Effect on oil quality. Fett/Lipid 1999, 7, 244-248.

Verleyen, T., Van Dyck, S., and Adams, C. A. (2005). Accelerated stability tests. Analysis of lipid oxidation. Champaign, USA.

Vujasinovic, V., Djilas, S., Dimic, E., Basic, Z., and Radocaj, O. (2012). The effect of roasting on the chemical composition and oxidative stability of pumpkin oil. European Journal of Lipid Science and Technology, 114(5), 568-574. 